\title{
Patient decision-making: medical ethics and mediation
}

\author{
Yvonne J Craig London School of Economics, University of London, Doctoral Research Graduate
}

\begin{abstract}
$A$ review of medical ethics literature relating to the importance of the participation of patients in decisionmaking introduces the role of rights-based mediation as a voluntary process now being developed innovatively in America. This is discussed in relation to the theory of communicative ethics and moral personhood. References are then made to the work of medical ethics committees and the role of mediation within these. Finally it is suggested that mediation is part of an eirenic ethic already being used informally in good patient care, and that there is a case for developing it further.
\end{abstract}

Professor Gillon's reflections on the 20th anniversary year of the birth of the fournal of Medical Ethics reminded us that "the importance of sharing discussions about the shared ethical dilemmas between doctors and nurses"1 was stated in its first issue. This also contained the Revd Dr Wilson's article, 'Communication with the dying', in which the importance of shared discussions with patients was given equal stress: "communication is mutual ... it is as important to acquire skill in human relationships as in materia medica". ${ }^{2}$

. Those of us who attended London Medical Group meetings at that time will remember the focus on the pioneer hospice work of Dr Cicely Saunders, or Dr Murray Parkes and others, where patient decision-making at the far edge of life was shown to be essential for holistic palliative care, yet recognised as being an ethically sensitive issue requiring great professional patience, compassion and understanding. Hence the purposeful ambiguity of the title of this present paper.

Its immediate purpose is to contribute to the current discourse within the National Health Service (NHS) and medical profession about the importance of resolving the many problems that are becoming increasingly numerous within it regarding patient care, and patients' complaints - for which mediation is becoming a recommended option.

\section{Key words}

Patient decision-making; mediation; medical ethics.
The ethics of resolving conflicts with regard to theiv age-rationing of treatment in an increasingly old andiw vulnerable population are presently being argued $\vec{s}$ about on a pragmatic basis by different consultants ${ }_{0}^{+}$ and practitioners in varied situations, with or without patient and relative involvement. The long $\overrightarrow{-} \vec{c}$ standing conflicts about types of intervention and supportive services for those who are terminally ill, ${ }^{\Phi}$ or in vegetative states are also increasing as theo public, patients and relatives become more educatedo about the choices which doctors have to make, ando in which they may wish to participate.

The Patients' Charter has also concentrated medical minds sharply on the increasing flow of conflicts which are flooding into NHS channels, $\frac{\Omega}{\mathbb{Q}}$ closely monitored by community health councils (CHCs). All NHS institutions have had to develop aO process of mediation or conciliation (an alternative ${ }_{-}$ term) although there is no standardisation yet of its administration, or of the training of the mediators most of whom appear to be lay volunteers with a generous annual honorarium. Some specific and separate NHS mediation services are being set up to 3 . reinforce the independence of the conflict resolutions work, but much of the rest is done in-house.

These three issues - age-rationing, services for theo terminally ill and for those in vegetative states - are just three of the many areas of conflict which areo polarising discussions within the NHS and the medical and nursing professions at the moment: they are threatening the excellent relationships which have, up until recently, always been enjoyed with of grateful and respectful public. Although the issueso are profoundly complex, with variables that change within the matrices of individual cases and collective्ठ resources, there is one critical common factor, whichs was noted in the opening paragraph of this paper:0 the vital importance of good communication? between patient and doctor.

My recent research into patients' complaints $\underset{\mathbb{D}}{\mathbb{D}}$ received in 1994 by one inner-city $\mathrm{CHC}$, whose areas was served by a large number of teaching hospitals showed that by far the greatest percentage inolveof "lack of communication and information". This is not an atypical finding. It upholds my own specialis work over the last ten years for the national voluntary 
organisation, MEDIATION UK, which overwhelmingly provides evidence that poor communication, or none, leads to unhealthy, unresolved conflicts which can escalate to cause unbearable interpersonal and interdisciplinary pressures that are distressing and destructive for all involved.

Hence the urgent need to consider the use of mediation skills which enable those involved to participate in constructive and conciliatory communication processes which encourage a problemsolving, not a blaming, approach to the conflicts that confront them. As mediation is based on the principle of voluntarism, enabling people to make choices and decisions in reaching their own mutual agreement about the issue or situation involved, the process is highly consistent with the values of contemporary medical ethics. Such a heuristic and beneficent communication process can only improve outcomes for patients and professionals alike because both are exposed to the conceptual and practical worlds of the other, and can develop shared understandings of the tasks to be faced.

One other important reason for advancing consideration of mediation in the field of medical ethics now is the critical contemporary concern to minimise heavy and intrusive social interventions into people's lives, in an epoch when bureaucratic regulatory activities are threatening to stifle personal and professional responsibility and creativity. Mediation is a minimal and voluntary form of offered intervention which can be variously developed to suit each unique individual or situation. Medical, nursing and paramedical staff can be trained in communication, negotiation or mediation skills so they can use these in their spheres of work. Independent mediators are available, usually at very low cost, when conflicts of interests are involved. Mediation does not threaten the autonomy of professionals, although it supports that of patients.

The rest of this paper tries to give substance to these introductory points, especially through its reference to advances in America, where, so far, the pioneer work has been done in this field. However, this introduction closes by returning to the role of the fournal of Medical Ethics and an early relevant reference to patient decision-making.

For the second issue of the journal showed its openness to critiques such as those of Dr Ivan Illich, namely his "medicalisation of life" and "iatrogenesis" theses. ${ }^{3}$ In a personal conversation he went so far as to say to me that he considered bereavement counselling to be ethically obscene, because professional intervention interfered with the role of the family. Interestingly, Buchanan and Brock used almost the same words. In qualified circumstances, they wrote, "due recognition of the family's role as decisionmaker requires non-interference". 4

Since those earlier days the journal has conspicuously advanced interdisciplinary discussion about patient decision-making in contributions by many distinguished authors. Parkin, in a recent issue, suggests that metaphysics and medical ethics have confusing languages, and asks whether the only relevant concepts are those "which aid practical decision-making ... make a difference to how we act". 5

This paper aims to extend discussion about patient decision-making by briefly exploring the way in which American medical ethics is now coming to regard the process of mediation as a practical problem-solving approach to the tensions of patientphysician relationships, as described by Veatch. ${ }^{6}$ There is also the sense in which there is mediation between the principles of autonomy, beneficence, non-maleficence and justice, first set forth in 1977, as Beauchamp and Walters remind us. ${ }^{7}$

\section{Mediation: a rights-based process}

It is timely to consider mediation in the United Kingdom because, although it has a long history in international diplomacy, it has just been socially institutionalised by the Lord Chancellor as the recommended way of dealing with family disputes. As mediation is essentially a voluntary service, national family mediation services stipulated that the original mandatory requirement was ethically unacceptable to them.

Although there is some understandable but mistaken concern amongst British lawyers that mediation is second-class justice, many are joining the movement, following the pattern of the earlier American professional migration in the 1960s. In the USA mediation, or alternative dispute resolution (ADR), as it is often called, is supported by the American Bar Association and the federal and state governments. It has expanded into every field of life and, most relevant to this journal, into areas of disability, guardianship, long-term care, ombudsman work and medical ethics.

For example, the 1990 Americans with Disabilities Act has been followed by federal funding of mediation projects to process claimants' rights if they choose this quick, low-cost way in preference to court action, which can take up to ten years to complete. It is stressed that mediation, as a rightsbased process, ensures how rights are to be enforced, not whether they should be.

Yet, since mediators are trained to be impartial and independent, they are equally concerned about the rights of all involved in the dispute: they are concerned to enable the views of all participants to be listened to, discussed and mutually reconciled, at least to the extent that participants reach their own agreement about resolving issues and determining outcomes. Mediation is a non-coercive and gentle process, well suited to patient decision-making, in both senses of the term.

Similarly, the principle of self-determination, as legalised in the US 1990 Patient Self-Determination 
Act, has received greater acknowledgement and respect through American recognition that mediation is an appropriate process whose use should be considered in some of the situational disputes which can occur over advance directives, and in medical ethics committees. The work of West and Gibson ${ }^{8}$ and Dubler and Marcus ${ }^{9}$ describe this, and that of the former will be referred to later in more detail.

However, first it is important to locate self-determination and mediation in the American academic bioethical debate about personhood and its relation to communication, noting that in Bioethics recently Blustein, ${ }^{10}$ and Kuczewski $^{11}$ have contributed articles to the discussion, while Goodman ${ }^{12}$ and Scott ${ }^{13}$ have written books on the subject.

\section{The discourse on communicative ethics}

Blustein reminds us that, through communication, "interpersonal compromise can be seen as a peculiarly liberal value grounded in respect for persons", ${ }^{10}$ compromise representing many agreements negotiated between disputing parties. Kuczewski puts the case against "the essential determination of persons" and describes the "communitarian model of self", 11 an ethical construction of personhood which conceptualises a socially communicating person who is a member of a family and community. We might say that a person is a social communicant, if not an ecclesiastical one.

Jecker similarly qualifies the self-determination of personhood through interpersonal communication by also arguing that "the family functions like a commons ... so that individual autonomy is not an absolute or uncompromising value in medical decisions". ${ }^{14}$ Larue encapsulates a view of many moral philosophers by saying that "the so-called Golden Rule recognises the individual as a choice-maker, and acknowledges the effect of choices on others", 15 implicitly affirming the communicative nature and responsibilities of humans, as well as their rights.

Moody, director of the New York Brookdale Center on Ageing, (a research centre of excellence), provides a theoretical base for the discourse on personhood, communication and bioethical conflicts. There is no need to rehearse the contentious issues which this journal regularly and fairly raises, but it is relevant to point to Moody's work on "communicative ethics" and "communicative action". ${ }^{16}$

"The value of a communicative ethic is to find commonly agreed-upon ways of negotiating our differences when we fail to agree on binding principles or rules." Here Moody acknowledges that normative and consensual values enshrined in cultural codes and laws are to be upheld, but says that, when differences arise, they benefit from being mediated in a "shared discourse among persons who respect the position of others in the communication process itself". ${ }^{16}$

Moody then goes on to develop the theme of "communicative action" which aims "to define and to promote the concrete conditions that promote $\frac{\text { m }}{5}$ such communication...". ${ }^{16}$ In his earlier work he has described the need for such "mediating structures", $17 \overrightarrow{\vec{F}}$ and affirmed the value of the mediation process in health care decision-making.

Most recently Waldman has developed a taxo- $\frac{\bar{\sigma}}{\overline{\frac{D}{}}}$ nomic approach to the role of mediation in medical $\vec{\Phi}$ ethics, arguing that "mediation is, by definition, $a \stackrel{2}{\circ}$ norm generating process" and that "ethical conflict ${ }^{\infty}$ in which no accepted ethical legal norm has emerged $\overrightarrow{0}$ to determine the ethical course of action" may $\overrightarrow{\vec{\omega}}$ provide the ideal type case for such intervention. ${ }^{18 \mathrm{c}}$

\section{Mediation in medical ethics committees}

It was at the Institute of Public Law, University of $\omega$ New Mexico School of Law, that West and Gibson $\vec{\sigma}$ made an investigative study of a sample of $20_{0}^{+}$ American medical ethics committees ${ }^{8}$ for the National Institute of Dispute Resolution (NIDR). $\vec{c}$ They found a variety of processes and practices in use, and that conflicts between professional ${ }^{\Phi}$ members of the committees were as serious, time- $\overrightarrow{0}$ consuming and difficult to resolve as those involving patients and relatives.

Even more importantly their research showed the "complicated network of sources of power" which affected staff and patients, including that derived from formal authority, expert information and $\frac{\circ}{\varnothing}$ association, control over resources and sanctions, and $\stackrel{\varrho}{\rightleftarrows}$ specific personal and moral power of professionals. ${ }^{8} \frac{\mathrm{O}}{3}$ Most relevant to this discussion is the confirmation $\frac{3}{\sqrt{5}}$ that procedural power, control over the procedures by which decisions are made, is critical to the conduct of medical ethics committees and, as Sherwin has suggested, should be more conducive to allowing $\stackrel{0}{\circ}$ patients control over their health. ${ }^{19}$

West and Gibson's study revealed many more salient facts which there is no space to consider here, $\supsetneq$ but these led to their recommendation that utilising 0 the mediation process would be beneficial in many situations. They also found that considerable interest in the ideas of mediation was shown by medical ethics committee members, who saw the o process as being entirely consistent with good $N$ practice, in their professional interests, and recog- N nised that it was already being used informally.

In some hospitals chaplains would play a mediating role; in others an ethics consultant, social worker $\frac{2}{\mathbb{D}}$ or designated team member would fulfil a similar $\stackrel{\odot}{+}$ function of facilitating communication. This 0 ensured that all those participating in a case review had their voices heard, that the elements of decision- $\stackrel{\mathbb{Q}}{\circ}$ making were clearly established and discussed, and $\mathbb{\Phi}$ that the best options for treatment and care were $\bar{\sigma}$ agreed, on as consensual a basis as possible.

The case for formal training in mediation was? recognised, as was that for the occasional use of an external and independent mediator, specially trained $\frac{0}{7}$

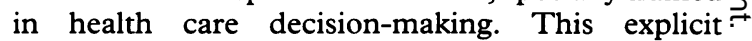


neutrality was seen to be more effective in achieving the balancing of unequal and hierarchical power relations, and in promoting the primacy of patients, whose lives had often been perceived as the objects, rather than the subjects, of negotiation.

Above all else, mediation, in both theory and practice, affirms the self-worth and achievement of patients by empowering them to contribute effectively to decision-making about their future, and by enabling them to feel whole and fulfilled in their personhood, if not physically healed. Mediation has been called a transformative as well as a rights-based process, ${ }^{20}$ and its holistic potentials can also nurture the professional and personal identities of hospital staff, salving the wounded healers.

\section{Mediation: an eirenic ethic}

In reviewing this brief introduction to the role of mediation in medical ethics some personal reflections may be permissible. When invited to take a seminar on the subject in one of America's largest public hospitals for long-term care, which included a hospice and an AIDS unit, I noticed that a significant number of the medical consultants in the large audience walked out shortly after I had begun my lecture. The reason, I discovered later, was that it had been advertised as "Medical Ethics and Medication", and mediation was obviously not on the horizon for those physicians. How open will British medicine prove to be in accommodating mediation within the shifting paradigm of patient decision-making?

In this respect, my own specialised research ${ }^{21}$ into the role of mediation in contributing to the prevention of elder abuse through dealing constructively with relational conflict at early stages, indicates the conservativeness of medicine in this tragic social area. Dr Gerry Bennett of the Royal London Hospital Trust is one of the few geriatricians who have done pioneer work in the diagnosis, treatment and care of sufferers. ${ }^{22}$ Few hospital accident/ emergency departments, or general practitioners in their statutory assessments of people over 75, are taught to consider the diagnostic category of elder abuse. Can British medicine cope with the flood of new concepts and concerns which are emerging?

Yet the Oxford Practice Skills Project ${ }^{23}$ has presaged the further development of a new paradigm for teaching, while Bird's observations of advocacy in the nursing context ${ }^{24}$ show that its limitations, as well as great values, indicate a lacuna which I suggest mediation can contribute to filling.

It is to be hoped that readers of the fournal of Medical Ethics will now contribute to a debate about the issues to which this present paper has tried to give a preliminary and provisional airing

Yvonne $\mathcal{F}$ Craig, $M A, \mathcal{F P}$, is a retired hospital social worker and counsellor and founder of the Elder
Mediation Project of the national voluntary organisation, MEDIATION UK. She is currently doing doctoral research at the London School of Economics.

\section{References}

1 Gillon R. Twenty years of the JME - reflections. fournal of Medical Ethics 1995; 21: 3-4.

2 Wilson M. Communication with the dying. Fournal of Medical Ethics 1975; 1: 18-21.

3 Illich I. The medicalisation of life. Fournal of Medical Ethics 1975; 1: 73-7.

4 Buchanan A, Brock D. Deciding for others: the ethics of surrogate decision-making. Cambridge: Cambridge University Press, 1979.

5 Parkin C. Metaphysics and medical ethics. Fournal of Medical Ethics 1995; 21: 106-11.

6 Veatch $R$. The patient-physician relation: the patient as partner. Bloomington and Indiana: Indiana University Press, 1991.

7 Beauchamp T, Walters L. Contemporary issues in bioethics. Belmont, California: Wadsworth Publishing Company, 1994.

8 West M, Gibson J. Facilitating medical ethics case review: what ethics committees can learn from mediation and facilitation techniques. Cambridge Quarterly on Health Care Ethics 1992; 1: 63-74.

9 Dubler N, Marcus L. Mediating bioethical disputes. New York United Hospital Fund, 1994.

10 Blustein J. Doing what the patient orders: maintaining integrity in the doctor-patient relationship. Bioethics. 1993; 7: 289-314.

11 Kuczewski M. Whose will is it, anyway? a discussion of advanced directives, personal identity and consensus in medical ethics. Bioethics. 1994; 8: 27-48.

12 Goodman M, ed. What is a person? Clifton, New Jersey: Humana Press, 1988.

13 Scott G. Moral personhood: an essay in the philosophy of moral psychology. Albany, New York: State University of New York, 1990.

14 Jecker N, ed. Aging and ethics: philosophical problems in gerontology. Clifton, New Jersey: Humana Press, 1991.

15 Larue G. Gero-ethics: a new vision of growing old in America. New York: Prometheus Books, 1992.

16 Moody $\mathrm{H}$. Ethics in an aging society. Baltimore: Johns Hopkins University Press, 1992.

17 Moody H. Abundance of life. New York: Columbia University Press, 1988.

18 Waldman E [unpublished paper]. Locating the role of mediation in medical ethics: a taxonomic approach. California, Western State University College of Law, California, 1995.

19 Sherwin S. No longer patient: feminist ethics and health care. Philadelphia: Temple University Press, 1992.

20 Folger J, Jones T, eds. New directions in mediation; communication, research and perspectives. London: Sage, 1994.

21 Craig Y. Elder mediation: can it contribute to the prevention of elder abuse and the protection of the rights of elders and their carers? Fournal of Elder Abuse and Neglect 1994; 6: 83-95.

22 Bennett G, Kingston P. Elder abuse: concepts, theories and interventions, London: Chapman \& Hall, 1993.

23 Hope T, Fulford K. The Oxford Practice Skills Project. fournal of Medical Ethics. 1994; 19: 229-34.

24 Bird A. Enhancing patient well-being: advocacy or negotiation? Fournal of Medical Ethics. 1994; 19: 152-6. 